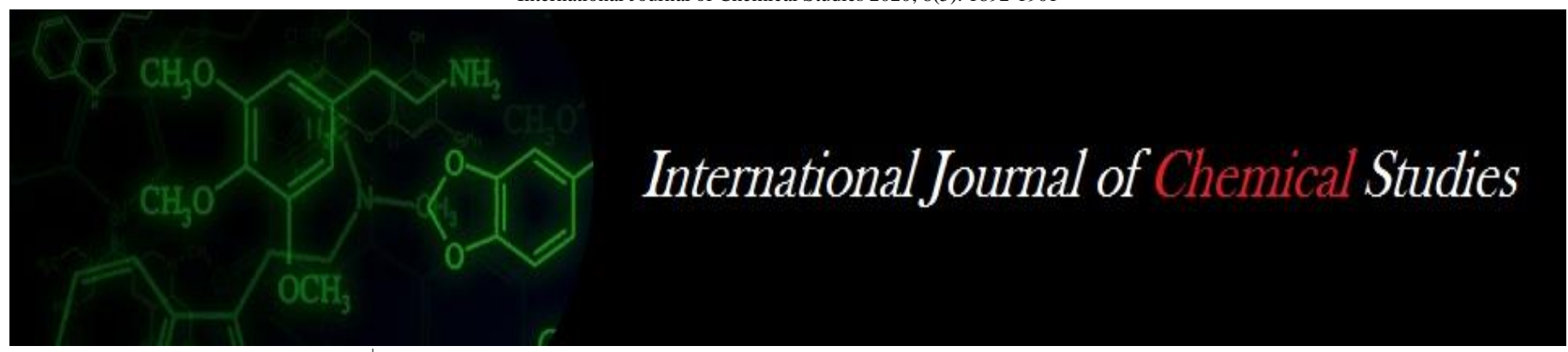

P-ISSN: 2349-8528

E-ISSN: 2321-4902

www.chemijournal.com

IJCS 2020; 8(5): 1892-1901

(C) 2020 IJCS

Received: 12-06-2020

Accepted: 10-08-2020

Shobha D Surbhaiyya

Ph.D. Research Scholar,

Biotechnology Centre,

Department of Agricultural

Botany, Post Graduate Institute,

Dr. Panjabrao Deshmukh Krishi

Vidyapeeth (State Agricultural

University), Akola,

Maharashtra, India

\section{SJ Gahukar}

College of Food Technology,

Yavatmal, Maharashtra, ladai,

India

\section{PV Jadhav}

Biotechnology Centre,

Department of Agricultural

Botany, Dr. Panjabrao

Deshmukh Krishi Vidyapeeth,

Maharashtra, India

\section{MP Moharil}

Biotechnology Centre,

Department of Agricultural

Botany, Dr. Panjabrao

Deshmukh Krishi Vidyapeeth,

Maharashtra, India

\section{NR Potdukhe}

Genetics and Plant Breeding,

Department of Agricultural

Botany, Dr. Panjabrao

Deshmukh Krishi Vidyapeeth,

Akola, Maharashtra, India

PK Singh

Divisional Genetics, Indian

Agriculture Research Institute,

Pusa Campus, New Delhi, India

Corresponding Author: Shobha D Surbhaiyya Ph.D. Research Scholar, Biotechnology Centre,

Department of Agricultural Botany, Post Graduate Institute, Dr. Panjabrao Deshmukh Krishi Vidyapeeth (State Agricultural

University), Akola,

Maharashtra, India

\section{Morpho-physiological character association studies of seedling traits in ten wheat (Triticum aestivum L.) genotypes under osmotic stress conditions}

\author{
Shobha D Surbhaiyya, SJ Gahukar, PV Jadhav, MP Moharil, NR \\ Potdukhe and PK Singh
}

DOI: https://doi.org/10.22271/chemi.2020.v8.i5z.10579

\begin{abstract}
In the past, many environmental stress especially water stress, negatively influenced the productivity and production of wheat (Triticum aestivum L.), one of the most important cereal crop in the world. Breeding current high yielding water stress tolerant wheat genotypes is a research priority specifically for these regions where climate change is predicted to result in more water stress conditions. A strategy that evaluates genotypes for physiological responses to water stress at earlier growth stages may be more targeted to water stress. Therefore, present investigation, ten wheat genotypes were screened following a completely randomized design under controlled condition. Different concentrations of PEG-6000 were used to induce osmotic stress at the germination growth stage. The analysis of variance indicated that significant differences among treatments for all seedling traits. All genotypes also differed significantly in germination percentage, shoot and root length, fresh and dry weight of shoot and root. Significant treatment interaction revealed that genotypes responded variably to osmotic stress treatments; hence provided better opportunity to select a water stress tolerant genotype at seedling growth stages. Data revealed a decreasing trend in values for all traits with the increasing concentration of PEG-6000. The relative minimum decrease over average due to osmotic stress was 9.04 percent in seed germination, 20.58 percent in shoot length, 9.01 percent in root length, 10.04 percent in shoot fresh weight, 3.30 percent in shoot dry weight, 11.57 percent in root fresh weight and 11.01 percent in root dry weight. However, relative decrease of individual genotype for various seedling traits might be more meaningful which indicated that genotype AKAW-5017 showed minimum reduction in root length, fresh root weight, dry root weight, fresh shoot weight and dry shoot weight while the minimum decline of seed germination and shoot length observed in AKAW- 3717. However, AKAW-4842, AKAW- 4907, and AKAW-4926 gave almost equally lower reduction for seed germination, root length, and shoot length and were consider as water stress tolerant. Correlation coefficient studies revealed considerable and positive correlation among seedling traits. The result indicated that increase in one trait may cause a simultaneous an increase in other traits; hence, selection for any of these seedling attributes will lead to developing water stress tolerant wheat genotypes.
\end{abstract}

Keywords: Triticum aestivum, water stress, genotypes, seedlings traits, PEG-6000

\section{Introduction}

In past year, globally wheat (Triticum aestivum $\mathrm{L}$ ) is second ranked most important cereal crop for staple food. Many environmental factors especially drought stress is considered to be one of the major constraints in worldwide which have negatively influenced the productivity and production (Ahmed et al., 2017) ${ }^{[7]}$. The effect of water stress on crop yield depends on stage of plant growth during which it occur. The most threatening problem in wheat production is the shortage of water at the seedling stage, mid-season water stress, terminal stress or a combination of any two or three. Seed germination and seedling growth characters are very important factors in determining yield (Rauf et al., 2006) ${ }^{[53]}$. Dhanda et al. (2004) [14] indicated that seed vigor index and shoot length are among the most sensitive to drought stress, followed by root length and coleoptiles length. The rate of seed germination and the final germination percentage as well as the amount of water absorbed by the seeds were considerably lowered with the rise of osmotic stress level (Heikal et al., 1981) ${ }^{[19]}$. 
There are many studies such as the selecting plant species or the seed treatments that are helpful for alleviating the negative effect of drought stress on plant (Ashraf et al., 1992; Almansouri et al., 2001; Okcu et al., 2005; Kaya et al., 2006; Iqbal and Ashraf, 2007) [2,3,49,31].

Identifying the water stress tolerant wheat genotypes at germination and early seedling growth stage under low osmotic pressure is practiced as a reliable physiological indicator by the researchers (Chachar et al., 2016) ${ }^{[12]}$. Hence, the investigation of water stress based on the germination of different genotypes is a forward step to identify the most tolerant genotypes under low osmotic potential. Selection for water stress tolerance at germination and the early seedling stage is frequently accomplished using simulated water stress induced by chemicals like polyethylene glycol (PEG 6000). It imposes water stress under in-vitro conditions that maintains uniform water potential throughout an experimental period, whereby a large set of genotypes can be screen accurately (Manoj and Uday, 2007) [44]. The advantage of using polyethylene glycol (PEG) compared to others osmotic solutions is that due to the high molecular weight (6000-8000) PEG cannot enter the plant cells, instead, the water is withdrawn from the cell and cell wall without affecting or hurting the cell structure (Van Berg and Zeng, 2006) ${ }^{[58]}$. While other osmotic solutions of low molecular weight could be toxic to plant as they are easily be taken by the plant (Hamza, 2012) ${ }^{[24]}$. Polyethylene glycol molecules are known to be inert, no-ionic, and virtually impermeable to cell membranes and can induce uniform water stress without causing direct physiological damage (Kulkarni and Deshpande, 2005) ${ }^{[32]}$. It can be used to modify the osmotic potential of nutrient clarification culture and thus pant water deficit in a relatively controlled manner (Lagerwerff et al., 1961; Money, 1989; Zhu et al., 1997; Lu and Neumann, 1998; Rauf et al., 2006; Van et al., 2006; Hamza, 2012) [38, 43, 59, 39, $53,58,24]$. PEG as a water stress causing factor can reduce water potential, resulting in the growth reduction of germinated seeds and seedling (Zhu et al., 2006) ${ }^{[60]}$. It is envisaged from the above findings that PEG solutions can be used in the laboratory for screening water stress resistant genotypes. Therefore, present experiment was designed to treat seeds of 10 wheat genotypes with different concentration $(0 \%, 15 \%$ and $25 \%$ ) of PEG solution for screening of water stress tolerance wheat genotypes under laboratory condition. The results showed that all genotypes of wheat have different responses to water stress, indicating that it is feasible to choose the best genotype for resisting water stress in controlled conditions. However, seeds treated with 25\% PEG did not germinate at all. The reason of this failure might be the high concentration of the chemical (PEG) which desiccated endosperm of the seeds rapidly, eventually they failed to grow (Khakwani et al., 2011; Baloch et al., 2012) [36, ${ }^{9]}$. Selection of physiological traits associated with the drought tolerance is essentially enhanced to increase the efficiency of selection (Ciuca et al., 2010) ${ }^{[10]}$. Screening for water stress tolerance based on the field trials is costly and timeconsuming, in addition to the typical condition required to express their effective genes responsible for the studied characteristics. Therefore, preliminary screening methods are commanded for the field criteria (Kim et al., 2001) ${ }^{[29]}$. Early screening as a physiological dissection of drought tolerance is one of the approaches to assist plant breeder in rapid detection of suitable genotype to be involved in the next breeding program.

\section{Materials and Methods 2.1 Plant material}

The experimental material of the present investigation comprised of ten genotypes of wheat (Triticum aestivum) procured from Wheat Research Unit Dr. Panjabrao Deshmukh Krishi Vidyapeeth Akola.

\subsection{Osmotic stress experiment}

The laboratory experiment was laid out in completely randomized design (CRD) with two factors: genotypes and water stresses. This study was conducted in a growth room of the Department of Botany (Biotechnology centre), Dr. Panjabrao Deshmukh Krishi Vidyapeeth, Akola, Maharashtra, India. Ten wheat genotypes were studied to see the effect of osmotic stress imposed by using polyethylene glycol (PEG) 6000. Three osmotic solutions (including distilled water) were applied during the germination period on the wheat genotypes with three replicates, using Poly ethylene glycol (PEG) of molecular weight 6000 . Solutions were prepared according to weight by volume i.e. T1, (control with distilled water), T2 (15\% PEG solution) and T3 (25\% PEG solution) by dissolving separately calculated amounts of PEG 6000 in distilled water $(0,15.0, \quad 25.0 \mathrm{~g}$ PEG 6000/100 ml), respectively, at $25^{\circ} \mathrm{C}$. Seeds were surface sterilized with 5 percent sodium hypochlorite solution for 15 minutes. Residual sodium hypochlorite solution was removed by thorough washing with sterilized distilled water. Whatman filter paper was used and moistened with $5 \mathrm{ml}$ PEG solution or distilled water. Twenty five seeds from each genotype with three replicates were placed in Petri dish $(90 \mathrm{~mm}$ diameter) for all treatments and were placed in growth room at $25 \pm 2{ }^{\circ} \mathrm{C}$ with 65 percent relative humidity for 10 days. Two $\mathrm{ml}$ of designated treatment solution was applied alternate days into each Petri dish after thorough washing and draining the previous left solution.

The germinated seeds were counted daily for the experiment duration, started from the second day after sowing. Seeds were considered germinated when they exhibited radicle extension more than $2 \mathrm{~mm}$. The following characteristics were measured:

- Germination Percentage (\%): Counted after $10^{\text {th }}$ days of treatment by using following formula:

Germination $\%=($ The number of germinated seeds /total number of seeds) $\times 100$

- Shoot Length (cm): Shoot length was measured with the help of scale by selecting ten seedlings randomly on the $10^{\text {th }}$ day of germination. Average length was used for statistical analysis.

- Root Length (cm): Average root length of ten randomly selected plants was recorded with the help of scale on the $10^{\text {th }}$ day of germination.

- Seedling vigor index: The seedling vigor of seed was assessed by the method suggested by Abdul baki and Anderson (1972) ${ }^{[1]}$ by using formula,

Seedling vigor $=$ Average percentage germination $\times$ Seedling length on the day of finalcount (root + shoot) (cm)

- Shoot fresh/dry and Root fresh/dry weight (g plant $\left.{ }^{-1}\right)$ : Ten days old plumules and radicles emerged under control and stresses were harvested. Immediately fresh weights were weighed and dried in hot air oven at $70^{\circ} \mathrm{C}$ till stable weight following which dry weights were measured. 


\subsection{Statistical analysis}

Data was subjected to analysis of variance (ANOVA), using OPSTAT software at both $1 \%$ and $5 \%$ level of probability. Cluster analysis based on squared Euclidean distance was also performed to classify the genotypes using UPGMA (Unweighted Pair Group Method for Arithmetic mean) for cluster analysis and dendrogram was generated as per the procedure given by (Nei and $\mathrm{Li}, 1979$ ). These computations were performed using the program XLSTAT software (www.xlstat.com).

\section{Result and Discussions}

\subsection{Seed germination $(\%)$}

Seedling emergence is one of the most sensitive growth stages that are resistance to water deficit. Therefore, seed germination is prerequisites for successful stand establishment of crop plants (Baloch et al., 2012) ${ }^{[9]}$. Under semiarid region, low moisture is frequently limiting factor during germination (Khakwani et al., 2011) ${ }^{[36]}$. Because of germination is on the most valuable trait for early seedling stage of crop plant, it seems that water stress condition had more sensitive than other genotypes (Homayoun et al., 2011) ${ }^{[23]}$. Earlier studies focalization, germination in solution with high osmotic potential is one of the most important laboratory methods suggested for screening water stress tolerance of crop plants (Rauf et al., 2006) ${ }^{[53]}$. Therefore, in the present investigation, ability of the ten wheat genotypes under chemical desiccation, induced by PEG (6000) during early seedling stage was assessed under in-vitro conditions. Data relevant the effect of osmotic stress induced by PEG on seed germination percentage (\%) as depicted in (Figure A, Plate 1). Data indicated that increase in osmotic stress caused a significant decrease in germination percentage in all genotypes under study (Table 1). Out of 10 genotypes tested, three genotypes (AKAW-3717, AKAW-4926 and AKAW-5017) showed maximum of $85 \%$ seed germination (Table 1). The average of germination percentage was $98.54 \%$ and $83.21 \%$ in unstressed and $15 \%$ osmotic stress treatment. AKAW-4907 exhibited better germination percentage $(99.93 \%)$ followed by AKAW-4925 (99.67\%) under unstressed condition whereas overall minimum germination percentage $(97.93 \%)$ recorded in AKAW-5010. Maximum germination percentage $(89.67 \%)$ was recorded in AKAW-3717 followed by AKAW-5017 $(87 \%)$ under $15 \%$ osmotic stress. AKAW-5012 exhibited minimum germination percentage $(77.33 \%)$ under osmotic stress condition. The genotype AKAW-3717 showed minimum reduction in germination percentage $(9.4 \%)$ followed by AKAW-5017 (12.34\%) under stress condition.

Germination is considered as one of the first and most fundamental life stage of a plant which contribute significantly in growth and yield production of wheat varieties. The resistance against water stress during the germination makes a plant stable, vigorous and healthy. Water stress results in late and reduced germination or might inhibit germination absolutely. Once a seed reaches a critical level of hydration it will head toward full germination. But it's also identified that physiological variations will arise under partial hydration when germination is prevented (Hunter and Erickson, 1952) ${ }^{[18]}$. The reduction in germination percentage was due to the effect of PEG 6000 that decreases the water potential gradient among seeds and their adjacent media and badly affects seed germination (Dodd and Donovan, 1999) [13]. Diverse genetic differences were found among the cultivars with respect to germination and there was a substantial decline in germination in all wheat cultivars.
Genotypes considered being water stress tolerant as their germination percentage did not reduce significantly with the increased moisture stress during germination, because some plants can develop their biochemical and physiological function to tolerate the water deficient condition (Chachar et al., 2016) ${ }^{[12]}$. These findings are in agreement with the outcomes of Harshvardhan et al. (2014) ${ }^{[25]}$ and Alaei et al. (2010) ${ }^{[4]}$ who reported that, with the increase in water stress, germination percentage is decreases. Good germination under water stress is an important parameter for screening different wheat varieties for drought resistance. So such varieties having good germination percentage and rate should be selected for good crop yield.

\subsection{Shoot length $(\mathrm{cm})$}

Shoot length continuously decreases by exposure to different osmotic stress levels. Water stress tolerance in genotype is described by slight decrease of shoot growth in water stress environments. Measurements of shoot length of seedling subjected to osmotic stress have been suggested for water stress tolerance (Ahmadizadeh et al., 2011) ${ }^{[5]}$. Shoot lengths were recorded after 10 days of seedling growth. All wheat genotypes showed variation in shoot length in response to the PEG induced stress (Table 1). In present study, data relevant the effect of osmotic stress induced by PEG on shoot length (cm) as illustrated in (Figure B, Plate 1). Increase in osmotic stress caused a substantial decrease in shoot length in wheat genotypes. Mean shoot lengths were 16.23 and $10.91 \mathrm{~cm}$ in unstressed and $15 \%$ osmotic stress respectively which clearly shows decrease over unstressed condition. Highest shoot length $(17.83 \mathrm{~cm})$ recorded in AKAW-3717 followed by AKAW-5017, AKAW-4842 (16.8 cm) and AKAW-5014 $(16.7 \mathrm{~cm})$ while lowest shoot length $(14.5 \mathrm{~cm})$ recorded in AKAW-3722. Shoot length is inversely proportional to water stress. AKAW-3717 gave better shoot length $(14.16 \mathrm{~cm})$ followed by AKAW-5017 (13.3cm) and AKAW-4842, AKAW-4926 (12.2 cm) under $15 \%$ osmotic stress condition. Minimum values of shoot length $(7.9 \mathrm{~cm})$ recorded in AKAW-4925 and AKAW-5012 at 15\% osmotic potential. The genotype AKAW-3717 showed minimum reduction in shoot length (20.58\%) followed by AKAW-5017 (20.83\%) under stress condition.

In wheat, seedling growth in laboratory environments has been recognized as appropriate growth phase for testing the drought tolerance. It could be speculated that presence of increased concentrations of PEG during the growth of seedling prevents the developmental traits and survival of wheat seedling. In the present study, larger decline in shoot length was recorded under stress conditions (at osmotic potential of $25 \%$ ). Similarly finding, presence of increased different concentration of PEG 6000 during the seedling growth stage had certainly reduced the shoot development. The water stress tolerant is qualified by a small reduction of shoot growth under water stressed condition (Moushachi et al., 2012) ${ }^{[46]}$. Also many researchers viz., Othmani et al., 2019; Soni et al., 2014; Perez et al., 2007; Okcu et al., 2005) $[50,54,51,49]$ documented that shoot growth reduced under water stressed conditions. All these findings are in accordance with the statement of Hsiao and Xu (2000) ${ }^{[21]}$; Munns and Sharp (1993) [42] conveyed that shoot growth was often more reduced than root growth under stress conditions, a phenomenon commonly found in dry soils.

\subsection{Root length $(\mathrm{cm})$}

Root length in wheat crop considered as the most powerful trait among the seed growth parameters in water stress 
tolerance selection program (Hassan et al., 2016) ${ }^{[26]}$. Root growth is an important parameter for plant tolerance to drought stress as roots are the main engine for meeting transpirational demand and play an important role in making water available to plants (Huang and Gao, 1999; Liu and Huang, 2000) ${ }^{[20,40]}$. A deeper and more extended root system allow the seedlings to extract more water in surrounded soil. Decrease in the root length might be resulted from the diminish relative turgidity and protoplasm dehydration, that brings down cell expansion and delaying the cell division (Mujtaba et al., 2016) ${ }^{[47]}$. Root lengths were recorded after 10 days of seedling growth (Table 1). In present study, data indicated that increase in osmotic stress caused a significant decrease in root length as presented in (Figure C, Plate 1). Maximum root length $(19.20 \mathrm{~cm})$ recorded in AKAW-5012 followed by AKAW-4907 (19.12 cm) and AKAW-5017 $(19.03 \mathrm{~cm})$ whereas minimum root length $(18.13 \mathrm{~cm})$ recorded in AKAW-4842. Root length decreased rapidly with increase in osmotic potential in wheat cultivars under study. AKAW-5017 gave better root length $(17.27 \mathrm{~cm})$ followed by AKAW-4926 $(16.83 \mathrm{~cm})$ and AKAW-3717 $(16.13 \mathrm{~cm})$ at $15 \%$ osmotic potential. Minimum values of root length (13.54 $\mathrm{cm})$ recorded in AKAW-3722 at $15 \%$ osmotic potential. The genotype AKAW-4926 showed minimum reduction in root length $(9.1 \%)$ followed by AKAW-5017 (9.28\%) under stress condition.

Root length of all cultivars used in the present study was significantly reduced by osmotic stress. Similar outcomes were experienced by Huang and Fu (2000) ${ }^{[22]}$. Differences in root length were also highly significant among cultivars. Root length is less affected by water stress as compared with shoot length. The halt in cell division and cell elongation resulted in tuberization ultimately causing decrease in root and shoot length. This results in adjustments in the root system which allows the plant to enter a static mode till the environment becomes favorable again (Fraser et al., 1990) ${ }^{[16]}$. When those varieties having elongated root length under water stress conditions reflected an adaptive reaction involving an increase in root length to reach deeper water in the soil suggested by Soni et al. (2014) ${ }^{[54]}$. Though root length was affected due to water stress, considerable reduction due to PEG at higher concentration (Othmani et al., 2019) ${ }^{[50]}$. The outcomes are in accordance with the findings of Perez et al. (2007) ${ }^{[51]}$ stated that water stress reduces the root growth.

\subsection{Shoot fresh weight ( $10^{-1}$ shoots)}

Osmotic stress caused a significantly decrease in shoot fresh weight of all genotypes under the present study (Table 2). Data relevant the effect of osmotic stress induced by PEG on shoot fresh weight $(\mathrm{g})$ as illustrated in (Figure D, Plate 1). AKAW-3717 exhibited maximum SFW (3.11 g) followed by AKAW-4842, AKAW-4926 and AKAW-5017 (3.00 g) whereas minimum SFW (2.95 g) recorded in AKAW-4907. Shoot fresh weight decreased, with increase in osmotic stress. AKAW-3717 exhibited better SFW (2.77 g) followed by AKAW-5017 (2.69 g) at 15\% osmotic potential. Least values of SFW (2.18 g) recorded in AKAW-4925 at 15\% osmotic potential. Water stress depresses the wheat shoot growth rather than root development. Moreover, distinct genetic differences were found among the genotypes with respect to shoot growth subjected PEG. Shoot fresh weight was more affected than root fresh weight. Shoot fresh weight showed that genotypes AKAW-3717 and AKAW-5017 were less affected as compared to other genotypes. The genotype AKAW-5017 showed minimum reduction in shoot fresh weight $(10.4 \%)$ followed by AKAW-3717 (11.12\%) while genotype AKAW- 4925 showed maximum reduction in shoot fresh weight under stress condition. The decrease in shoot biomass was attributed to lesser number and development of reduced leaves with increased concentration of PEG in the growing medium. Similarly findings by Kaydan and Yagmur (2008) ${ }^{[33]}$; Kamran et al. (2009) ${ }^{[34]}$ and Khan et al. (2013) ${ }^{[37]}$ revealed that shoot fresh weight is adversely affected under the stress environment.

\subsection{Shoot dry weight (g $10^{-1}$ roots)}

Data relevant the effect of osmotic stress induced by PEG on shoot fresh weight (g) as illustrated in (Table 2). The effect of osmotic stress on shoot fresh weight (SDW) of wheat genotypes presented in (Figure E, Plate 1). AKAW-3717 gave maximum SDW (2.56 g) followed by AKAW-5017 (2.50 g) whereas minimum SDW (2.03 g) recorded in AKAW-4926. Shoot dry weight decreased, with increase in osmotic stress. AKAW-3717 exhibited better SDW (2.41 g) followed by AKAW-5017 (2.35 g) at 15\% osmotic potential respectively. AKAW-4925 gave least values of SDW (1.56 g) at 15\% osmotic potential. Water stress adversely affects the shoot growth of wheat genotypes. The genotype AKAW-4926 showed minimum reduction in shoot fresh weight $(2.80 \%)$ followed by AKAW-4907 (3.30\%) while genotype AKDW5012 (31.4) showed maximum reduction in shoot fresh weight under stress condition. Genetic variations were recorded among the genotype with respect to shoot growth subjected to osmotic stress conditions. Shoot dry weight is more affected than root dry weight. Shoot dry weight indicated that genotypes AKAW-4926, AKAW-5017 were less affected as compared to other genotypes. The decline in shoot biomass was due to water stress. The outcomes are in agreement with the results of Khan et al. (2010) ${ }^{[35]}$ reported that shoot dry weight is affected due to osmotic stress

\subsection{Root fresh weight (g $10^{-1}$ shoots)}

Data relevant the effect of osmotic stress induced by PEG on root fresh weight (g) as depicted in (Figure F, Plate 1). Osmotic stress produced a significant decrease in RFW of all wheat genotypes presented in Table 3. AKAW-5017 exhibited maximum RFW (2.81 g) followed by AKAW-4842 (2.78 g) and AKAW-3717 (2.75 g) whereas minimum RFW (2.49 g) recorded in AKAW-5012. Increases in osmotic stress caused a remarkable decrease in RFW. AKAW-3717 gave better RFW (2.42 g) followed by AKAW-5017 (2.39 g) and AKAW-5014 (2.35 g) at $15 \%$ osmotic potential of respectively. AKAW-5012 and AKAW-4925 gave least values of RFW (1.70 g and $1.78 \mathrm{~g})$ at $15 \%$ osmotic potential respectively. The genotype AKAW-5017 showed minimum reduction in shoot fresh weight $(11.7 \%)$ followed by AKAW5017 (12.04\%) while genotype AKDW- 5012 (31.05) showed maximum reduction in shoot fresh weight under stress condition. Water stress drastically reduces the root fresh weight in wheat seedling. Seedling survival in drought prone environments may depend upon the species ability to compensate for the negative effect of low water potentials in the soil and atmosphere by adjusting root and shoot morphological and physiological patterns (Kramer, 1983; Morgan, 1984) ${ }^{[28,41]}$. The results obtained in this study reveal that RFW is more affected than that of dry weight and are in agreement with the results obtained by Murillo-Amador et al. (2002) ${ }^{[45]}$ in cowpea. These results correlates with finding with Sayar et al. (2010) ${ }^{[35]}$ who found that osmotic stress caused a significant decrease in root fresh weight in all genotypes. 


\subsection{Root dry weight (g $10^{-1}$ roots)}

The effect of osmotic stress on root dry weight (RFW) of wheat genotypes significantly decreased as illustrated in Table 3. Genotypes respond differently to various levels of osmotic stress for RDW as presented in (Figure G, Plate 1). AKAW-3717 gave maximum RDW (2.04 g) followed by AKAW-4907, AKAW-4926 (1.99 g) and AKAW-5017 (1.90 g) whereas minimum RDW (1.74 g) recorded in AKAW4925. Root dry weight deceased, with increase in osmotic stress. AKAW-4842 exhibited better RDW (1.80 g) followed by AKAW-3717 (1.78 g) at $15 \%$ osmotic potential respectively. AKAW-4925 gave least values of RDW (1.19 g) at $15 \%$ osmotic potential. Seedling dry weight indicated that cultivar AKAW-3717 was less affected by drought stress as compared to other cultivars. The genotype AKAW-4842 showed minimum reduction in shoot fresh weight $(11.1 \%)$ followed by AKAW-5017 (12.04\%) while genotype AKDW5017 (32.72) showed maximum reduction in shoot fresh weight under stress condition. Water stress adversely affects the root dry weight. Moreover, diverse genetic differences were found among the cultivars with respect to seedling growth subjected PEG. Root dry weight is less affected than fresh weight. The outcomes obtained in this study revealed that dry mass was less affected than fresh weight and results are in agreement with the findings of Bayoumi et al. (2008) ${ }^{[8]}$; Ahmad et al. (2017) ${ }^{[7]}$ who reported that osmotic stress caused significant effects on root dry weight in all genotypes.

\subsection{Correlation coefficient among seedling traits}

Correlation analysis is one the most important statistical parameters for selection and crop improvement. Correlation analysis revealed that shoot length exhibited significant and positive correlation with root length $(0.71)$, fresh root weight (0.86), fresh root weight (0.93), dry shoot weight (0.94), dry root weight (0.86) and germination percentage (0.80) (Table 4) which indicated that by increasing these attributes, shoot length will increase. Correlation coefficients illustrated that root length showed highly positive and significant association with fresh shoot weight (0.50), fresh root weight (0.74), dry shoot weight $(0.65)$, dry root weight $(0.62)$ and germination percentage $(0.51)$. Fresh shoot weight showed significant correlation with fresh root weight $(0.75)$, dry shoot weight $(0.89)$, dry root weight $(0.83)$ and germination percentage (0.73).

Fresh root weight showed significant correlation with dry shoot weight (0.92), dry root weight (0.90) and germination percentage (0.77). Dry shoot weight exhibited significant and positive correlation with dry root weight (0.91) and germination percentage $(0.81)$. Positive and highly significant correlation was observed between shoot length and dry shoot weight (0.94). These finding led to the conclusion that desirable traits possessed by different genotypes can be used for the development of water stress tolerant wheat genotypes. Khan et al. (2002) ${ }^{[30]}$ and Khan et al. (2013) ${ }^{[37]}$ reported that germination percentage exhibited positive and significant correlation with root length, fresh shoot weight, dry shoot weight, and dry root weight. Many researchers (Rakesh et al.,1998; Noorka et al., 2007 and Ahmad et al., 2013) [52, 48, 6] reported that genotypes showed variable response for water stress related traits under different stress level.

\subsection{Clustering of genotypes based on physiological parameters from laboratory screening using xlstat software (Gower coefficient)}

The differences in the responses to water stress by wheat genotypes was measured by employing xlstat software. Based on the physiological screening data, all the genotypes were grouped into four clusters, signaling the difference response of wheat genotypes to osmotic stress. Cluster IV had the maximum number of genotypes (4) followed by cluster II (3) and cluster I (2). The cluster III is monogenotypic. The ten genotypes grouping into four clusters are illustrated in Table 5. Clustering of wheat genotypes based on the physiological screening under laboratory condition using PEG-6000 is presented in Figure 1. The tolerant genotypes were grouped in cluster I while moderate tolerant and susceptible genotypes grouped in cluster II, III and IV. Gower method was found to be a useful tool in assessing the relative contribution of various physiological parameters in wheat genotypes under water stress and it may be used to select genetically superior genotype for breeding water stress tolerant lines. The contribution of each character towards the variation in response to water stress in wheat genotypes is depicted in Table 6 . The seed germination $(83.20 \%)$ contributed highest. Thus, seed germination may be given high emphasis while screening large number of genotypes for their water stress tolerant ability. This is contradictory with Ashraf et al. (1992) ${ }^{[2]}$ reported that under water stress condition, seed germination is not the standard for predicting plants showed water stress tolerance. Other characters like root length (15.68\%), shoot length $(10.90 \%)$, fresh shoot weight $(2.45 \%)$, fresh root weight $(2.11 \%)$, dry shoot weight $(1.96 \%)$ and dry root weight $(1.51 \%)$ contributed very little. The response of genotypes may be varying to different factors, which could be reflected in their respective seed performances.

Cluster analysis has been utilized to elucidate the disparity and assemble the genotypes based on water stress tolerance indices (El-Mohsen et al., 2015) ${ }^{[15]}$. Similarly, finding Ahmad et al. (2017) ${ }^{[7]}$ and Guoth et al. (2009) ${ }^{[17]}$ stated that the germination test is found to be useful for identifying the genotypes capable of quickly establishing themselves under low soil moisture conditions which shows correlation with water stress tolerance. The present investigation for screening water stress tolerance ability of wheat genotypes was found to be relevant in choosing the best accession for tolerant water stress. PEG-6000 is considered as the best macromolecular compound to stimulate water stress and it is widely used in water stress physiology and genetic mechanism for plants (Christmann et al., 2005; Verslues and Bray 2004; 2006) [11, 56,57]. 
Table 1: Effect of PEG on seed germination percentage (\%), shoot length and root length $(\mathrm{cm})$

\begin{tabular}{|c|c|c|c|c|c|c|c|c|c|}
\hline \multirow[b]{2}{*}{ Genotypes } & \multicolumn{3}{|c|}{ Seed germination $(\%)$} & \multicolumn{3}{|c|}{ Shoot length $(\mathrm{cm})$} & \multicolumn{3}{|c|}{ Root length (cm) } \\
\hline & $\begin{array}{c}\text { US } \\
(\mathbf{0 \%})\end{array}$ & $\begin{array}{c}\mathbf{S} \\
(\mathbf{1 5 \%})\end{array}$ & $\begin{array}{c}\% \\
\text { DOS }\end{array}$ & $\begin{array}{c}\text { US } \\
(\mathbf{0 \%})\end{array}$ & $\begin{array}{c}\mathbf{S} \\
(\mathbf{1 5 \%})\end{array}$ & $\begin{array}{c}\% \\
\text { DOS }\end{array}$ & $\begin{array}{c}\text { US } \\
(0 \%)\end{array}$ & $\begin{array}{c}\mathrm{S} \\
(15 \%)\end{array}$ & $\begin{array}{c}\% \\
\text { DOS }\end{array}$ \\
\hline AKAW-3717 & 99.07 & 89.67 & 9.4 & 17.83 & 14.16 & 20.58 & 19.10 & 16.17 & 13.36 \\
\hline AKAW-3722 & 96.66 & 81.44 & 15.74 & 14.5 & 8.17 & 43.66 & 19.03 & 13.54 & 31.90 \\
\hline AKAW-4842 & 99.52 & 80.17 & 12.42 & 16.8 & 12.3 & 26.79 & 18.13 & 16.13 & 11.02 \\
\hline AKAW-4907 & 99.93 & 84.15 & 16.78 & 15.9 & 10.3 & 35.22 & 19.12 & 15.14 & 20.91 \\
\hline AKAW-4925 & 99.67 & 80.73 & 18.99 & 14.8 & 7.9 & 46.62 & 18.63 & 15.80 & 15.20 \\
\hline AKAW-4926 & 98.13 & 85.33 & 10.13 & 16.3 & 12.3 & 24.54 & 18.5 & 16.83 & 9.01 \\
\hline AKAW-5010 & 97.93 & 82.13 & 16.12 & 17 & 10.5 & 38.24 & 18.33 & 14.50 & 24.90 \\
\hline AKDW-5012 & 98.7 & 77.33 & 21.64 & 15.5 & 7.9 & 49.03 & 19.20 & 15.13 & 21.18 \\
\hline AKAW-5014 & 96.63 & 84.14 & 12.61 & 16.7 & 12.2 & 26.95 & 18.43 & 16.3 & 11.57 \\
\hline AKAW-5017 & 99.25 & 87 & 12.34 & 16.8 & 13.3 & 20.83 & 19.03 & 17.27 & 9.28 \\
\hline Average & 98.54 & 83.21 & 13.62 & 16.23 & 10.91 & 33.25 & 18.75 & 15.68 & 16.83 \\
\hline $\begin{array}{c}\mathrm{SE}(\mathrm{m}) \\
\text { Factor } \mathrm{A} \\
\text { Factor } \mathrm{B} \\
\text { Factor }(\mathrm{A} \times \mathrm{B})\end{array}$ & \multicolumn{2}{|c|}{0.23} & $\begin{array}{l}- \\
- \\
-\end{array}$ & \multicolumn{2}{|c|}{0.12} & $\begin{array}{l}- \\
- \\
-\end{array}$ & 0.01 & $\begin{array}{l}01 \\
03 \\
04\end{array}$ & $\begin{array}{l}- \\
- \\
-\end{array}$ \\
\hline $\begin{array}{c}\mathrm{CD} \\
\text { Factor } \mathrm{A} \\
\text { Factor } \mathrm{B} \\
\text { Factor }(\mathrm{A} \times \mathrm{B})\end{array}$ & & & $\begin{array}{l}- \\
- \\
-\end{array}$ & & $\begin{array}{l}33 \\
74 \\
05\end{array}$ & $\begin{array}{l}- \\
- \\
-\end{array}$ & & $\begin{array}{l}04 \\
08 \\
12\end{array}$ & $\begin{array}{l}- \\
- \\
-\end{array}$ \\
\hline $\mathrm{CV}$ & \multicolumn{2}{|c|}{1.45} & - & \multicolumn{2}{|c|}{0.16} & - & \multicolumn{2}{|c|}{0.12} & - \\
\hline
\end{tabular}

Note: Average, CD and SE (m) were calculated using replicated data in the observations, Significant at 0.01 probability level: DOS (Decreased over stressed); US- Unstressed; S- Stressed

Table 2: Effect of PEG on shoot fresh and dry weight (g)

\begin{tabular}{|c|c|c|c|c|c|c|}
\hline \multirow[b]{2}{*}{ Genotypes } & \multicolumn{3}{|c|}{ Shoot fresh weight (g) } & \multicolumn{3}{|c|}{ Shoot dry weight (g) } \\
\hline & $\begin{array}{c}\text { Unstressed } \\
(0 \%)\end{array}$ & $\begin{array}{c}\text { Stressed } \\
(15 \%)\end{array}$ & $\begin{array}{c}\% \\
\text { DOS }\end{array}$ & $\begin{array}{c}\text { Unstressed } \\
(0 \%)\end{array}$ & $\begin{array}{c}\text { Stressed } \\
(15 \%)\end{array}$ & $\begin{array}{c}\% \\
\text { DOS }\end{array}$ \\
\hline AKAW-3717 & 3.11 & 2.77 & 11.12 & 2.56 & 2.41 & 5.90 \\
\hline AKAW-3722 & 2.95 & 2.35 & 20.41 & 2.27 & 1.68 & 26.2 \\
\hline AKAW-4842 & 3.0 & 2.57 & 15.40 & 2.35 & 2.11 & 5.47 \\
\hline AKAW-4907 & 2.83 & 2.41 & 14.77 & 2.12 & 2.04 & 3.30 \\
\hline AKAW-4925 & 2.89 & 2.18 & 24.61 & 2.22 & 1.56 & 29.5 \\
\hline AKAW-4926 & 3.0 & 2.51 & 12.55 & 2.03 & 1.98 & 2.80 \\
\hline AKAW-5010 & 2.97 & 2.41 & 18.51 & 2.3 & 1.76 & 23.3 \\
\hline AKDW-5012 & 2.92 & 2.32 & 20.74 & 2.37 & 1.63 & 31.4 \\
\hline AKAW-5014 & 3.0 & 2.34 & 22.09 & 2.32 & 2.08 & 6.20 \\
\hline AKAW-5017 & 3.0 & 2.69 & 10.4 & 2.50 & 2.35 & 5.90 \\
\hline Average & 2.90 & 2.30 & 18.36 & 2.31 & 1.98 & 14.01 \\
\hline $\begin{array}{c}\mathrm{SE}(\mathrm{m}) \\
\text { Factor } \mathrm{A} \\
\text { Factor } \mathrm{B} \\
\text { Factor }(\mathrm{A} \times \mathrm{B})\end{array}$ & \multicolumn{2}{|c|}{0.02} & $\begin{array}{l}- \\
- \\
-\end{array}$ & & & $\begin{array}{l}- \\
- \\
-\end{array}$ \\
\hline $\begin{array}{c}\mathrm{CD} \\
\text { Factor } \mathrm{A} \\
\text { Factor } \mathrm{B} \\
\text { Factor }(\mathrm{A} \times \mathrm{B})\end{array}$ & \multicolumn{2}{|c|}{0.05} & $\begin{array}{l}- \\
- \\
-\end{array}$ & & & $\begin{array}{l}- \\
- \\
-\end{array}$ \\
\hline $\mathrm{CV}$ & \multicolumn{2}{|c|}{0.05} & - & \multicolumn{2}{|c|}{4.4} & - \\
\hline
\end{tabular}

Note: Average, CD and SE (m) were calculated using replicated data in the observations, Significant at 0.01 probability level: DOS (Decreased over stressed)

Table 3: Effect of PEG on root fresh and dry weight $(\mathrm{g})$

\begin{tabular}{|c|c|c|c|c|c|c|}
\hline \multirow{2}{*}{ Genotypes } & \multicolumn{3}{|c|}{ Root fresh weight $\mathbf{( g )}$} & \multicolumn{3}{c|}{ Root dry weight $\mathbf{( g )}$} \\
\cline { 2 - 7 } & $\begin{array}{c}\text { Unstressed } \\
\mathbf{( 0 \% )}\end{array}$ & $\begin{array}{c}\text { Stressed } \\
\mathbf{( 1 5 \% )}\end{array}$ & $\begin{array}{c}\mathbf{\%} \\
\mathbf{D O S}\end{array}$ & $\begin{array}{c}\text { Unstressed } \\
\mathbf{( 0 \% )}\end{array}$ & $\begin{array}{c}\text { Stressed } \\
(\mathbf{1 5 \% )}\end{array}$ & $\begin{array}{c}\mathbf{\%} \\
\mathbf{D O S}\end{array}$ \\
\hline AKAW-3717 & 2.75 & 2.42 & 12.04 & 2.04 & 1.78 & 12.93 \\
\hline AKAW-3722 & 2.51 & 1.84 & 26.61 & 1.78 & 1.29 & 27.52 \\
\hline AKAW-4842 & 2.78 & 2.31 & 12.53 & 2.0 & 1.80 & 11.01 \\
\hline AKAW-4907 & 2.68 & 2.19 & 16.59 & 1.99 & 1.67 & 16.20 \\
\hline AKAW-4925 & 2.49 & 1.78 & 27.98 & 1.74 & 1.27 & 27.41 \\
\hline AKAW-4926 & 2.71 & 2.38 & 12.32 & 1.99 & 1.61 & 19.21 \\
\hline AKAW-5010 & 2.57 & 1.82 & 30.19 & 1.82 & 1.32 & 27.58 \\
\hline AKDW-5012 & 2.49 & 1.70 & 31.05 & 1.77 & 1.19 & 32.72 \\
\hline AKAW-5014 & 2.62 & 2.35 & 12.38 & 1.89 & 1.46 & 22.79 \\
\hline AKAW-5017 & 2.81 & 2.39 & 11.57 & 1.97 & 1.73 & 12.84 \\
\hline
\end{tabular}




\begin{tabular}{|c|c|c|c|c|c|c|}
\hline Average & 2.64 & 2.17 & 18.69 & 1.90 & 1.51 & 21.02 \\
\hline $\mathrm{SE}(\mathrm{m})$ & \multirow{2}{*}{\multicolumn{2}{|c|}{0.03}} & & \multirow{2}{*}{\multicolumn{2}{|c|}{0.01}} & \\
\hline Factor A & & & - & & & - \\
\hline Factor B & \multicolumn{2}{|c|}{0.07} & - & \multicolumn{2}{|c|}{0.02} & - \\
\hline Factor $(\mathrm{A} \times \mathrm{B})$ & \multicolumn{2}{|c|}{0.09} & - & \multicolumn{2}{|c|}{0.03} & - \\
\hline $\mathrm{CD}$ & \multirow{2}{*}{\multicolumn{2}{|c|}{0.01}} & & \multirow{2}{*}{\multicolumn{2}{|c|}{0.03}} & \\
\hline Factor A & & & - & & & - \\
\hline Factor B & \multicolumn{2}{|c|}{0.02} & - & \multicolumn{2}{|c|}{0.06} & - \\
\hline Factor $(\mathrm{A} \times \mathrm{B})$ & \multicolumn{2}{|c|}{0.03} & - & \multicolumn{2}{|c|}{0.09} & - \\
\hline $\mathrm{CV}$ & \multicolumn{2}{|c|}{0.05} & - & \multicolumn{2}{|c|}{3.30} & - \\
\hline
\end{tabular}

Note: Average, CD and SE (m) were calculated using replicated data in the observations, Significant at 0.01 probability level: DOS (Decreased over stressed)

Table 4: Correlation coefficients among various seedling traits of wheat genotypes treated with polyethylene glycol (PEG-6000) under in vitro condition.

\begin{tabular}{|c|c|c|c|c|c|c|}
\hline & SL & RL & FSW & FRW & DSW & DRW \\
\hline RL & $0.71^{* *}$ & & & & & \\
\hline FSW & $0.86^{* *}$ & $0.50^{* *}$ & & & & \\
\hline FRW & $0.93^{* *}$ & $0.74^{* *}$ & $0.75^{* *}$ & & & \\
\hline DSW & $0.94^{* *}$ & $0.65^{* *}$ & $0.89^{* *}$ & $0.92^{* *}$ & & \\
\hline DRW & $0.86^{* *}$ & $0.62^{* *}$ & $0.83^{* *}$ & $0.90^{* *}$ & $0.91^{* *}$ & \\
\hline GP & $0.80^{* *}$ & $0.51^{* *}$ & $0.73^{* *}$ & $0.77^{* *}$ & $0.82^{* *}$ & $0.67^{* *}$ \\
\hline
\end{tabular}

SL- shoot length; RL- root length; FSW- fresh shoot weight; FRW- fresh root weight; DRW- dry shoot weight; DRW- dry root weight; GP- Germination percentage; $* *$ indicate significance at the 0.01 probability levels.

Table 5: Clustering of genotypes based on physiological parameters from laboratory screening

\begin{tabular}{|c|c|c|}
\hline SN & Cluster & Name of genotypes \\
\hline 1 & Cluster I & AKAW-3717, AKAW-5017 \\
\hline 2 & Cluster II & AKAW-3722, AKAW-4925, AKAW-5012 \\
\hline 3 & Cluster III & AKAW-4842 \\
\hline 4 & Cluster IV & AKAW-4907, AKAW-4926, AKAW-5010, AKAW-5014 \\
\hline
\end{tabular}

Table 6: Contribution of different parameters from physiological screening using PEG-6000 in wheat genotypes under laboratory condition

\begin{tabular}{|c|c|c|}
\hline SN & Source & Contribution \\
\hline 1 & Seed germination percentage & $83.21 \%$ \\
\hline 2 & Shoot Length & $10.90 \%$ \\
\hline 3 & Root Length & $15.68 \%$ \\
\hline 4 & Fresh shoot weight & $02.46 \%$ \\
\hline 5 & Fresh root weight & $02.19 \%$ \\
\hline 6 & Dry shoot weight & $01.96 \%$ \\
\hline 7 & Dry root weight & $01.51 \%$ \\
\hline
\end{tabular}

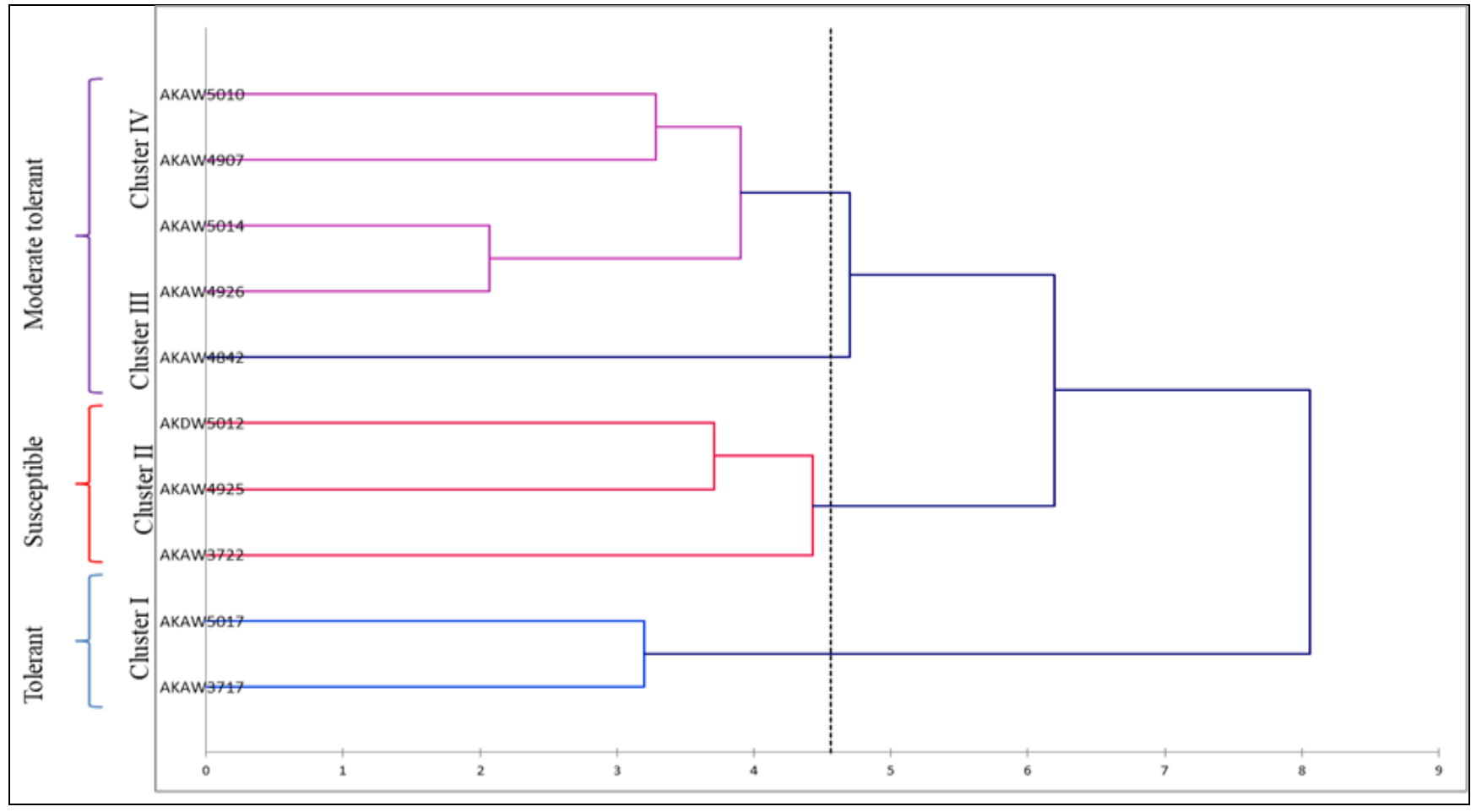

Fig 1: Cluster analysis of seedling traits under osmotic stress condition 


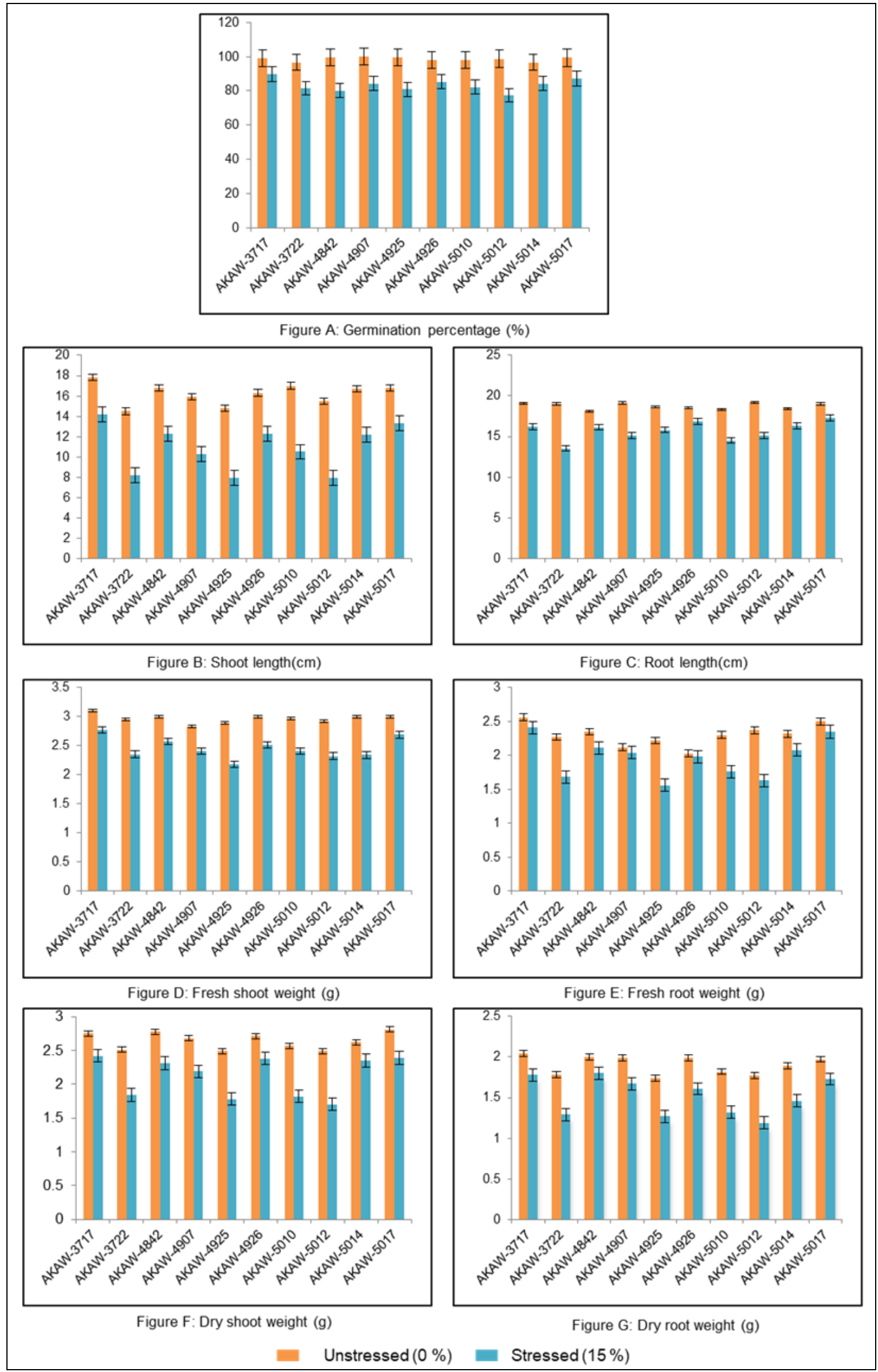

Plate 1: Physiological analysis of whet genotypes in response to stress using PEG-6000

\section{Conclusion}

The present work was conducted to evaluate the genetic potential of six wheat genotypes through artificially created osmotic stress by PEG-6000 in laboratory conditions followed by selection of genotypes based on easily measurable and inherited seedling traits contributing to water stress tolerance indices. In this study osmotic stress caused significant effect on all the seedling traits. 
However, the effect on individual genotype was more meaningful which that genotype AKAW-3717 showed very less reduction in all seedling traits while minimum reduction was recorded in AKAW-5017. Similarly, AKAW-4926 and AKAW-4842 expressed minimum reduction in shoot/root fresh/dry weight suggesting their higher stress tolerant, so these seedling traits may be used as good indicator for water stress tolerance. Furthermore, significant and positive correlation among seedling traits depicted that by improving dry weight will improve the overall performance of the crop. Cluster analysis discriminate the genotypes at different level osmotic stress through the studied characteristics. Selection can be made on the basis of seedling traits to screen a large population for water stress. It would be cost effective, less time consuming and less laborious to select the germplasm at early stage. So is suggested that the findings may be helpful for selection of water stress tolerance wheat genotype under the deliberated traits. The genotypes with improved traits may be used as parents in wheat breeding for moisture stress conditions.

\section{References}

1. Abdul-Baki AA, Anderson JD. Viability and leaching of sugars from germinating barley. Crop Science. 1970; 10:31-34.

2. Ashraf M, Bokhari H, Cristiti SN. Variation in osmotic adjustment of lentil (Lens culimaris Medic) in response to drought. Acta Botany Neerlandica. 1992; 41:51-62.

3. Almansouri M, Kinet JM, Lutts S. Effect of salt and osmotic stresses on germination in durum wheat (Triticum aestivum L.). Plant Soil. 2001; 231:243-254.

4. Alaei M, Zaefizadeh M, Khayatnezhad M, Alaei Z, Alaei Y. Evaluation of germination properties of different durum wheat genotypes under osmotic stress. MiddleEast J0urnal Science Research. 2010; 6(6):642-646.

5. Ahmadizadeh M, Shahbazi H, Valizadeh M, Zaelizadeh M. Genetic diversity of durum wheat indices using multivariate analysis under normal irrigation and drought stress condition. African Journal Agricultural Research. 2011; 6(10):2294-2302.

6. Ahmad M, Shabbir G, Minhas N, Shah M. Identification of drought tolerant wheat genotypes based on seedling traits. Sarhad Journal Agriculture. 2013; 29(1):21-27.

7. Ahmad NS, Shadia HS, Kamil MM, Dastan AA. Early screening of some Kurdistan wheat (Triticum aestivum L.) cultivars under drought stress. Journal of Agriculture Science. 2017; 9(2):88-103.

8. Bayoumi T, Eid MH, Metwali E. Application of physiological and biochemical indices as a screening technique for drought tolerance in wheat genotypes. African Journal of Biotechnology. 2008; 7(14):23412352.

9. Baloch MJ, Dunwell J, Khakwan AA, Dennett M, Jatoi WA, Channa SA. Assessment of wheat cultivars for drought tolerance via osmotic stress imposed at early seedling growth stages. Journal of Agricultural Research. 2012; 50(3):299-310.

10. Ciuca M, Banica C, David M, Saulescu NN. SSR markers associated with the capacity for osmotic adjustment in wheat (Triticum aestivum L.). Romanian Agriculture Research. 2010; 27(1):1-5.

11. Christmann A, Hoffmann T, Teplova I. Generation of active pools abscisic acid revealed by in vivo imaging of water-stressed Arabidopsis. Plant Physiology. 2005; 1:209-219.
12. Chachar Z, Chachar NA, Chachar QI, Mujtaba SM, Chachar GA, Sadaruddin C. Identification of drought tolerant wheat genotypes under water deficit conditions. International Jounal Agricultural Research Granthaalayaah. 2016; 4(2):206-2014.

13. Dodd L, Donovan LA. Water potential and ionic effects on germination and seedling growth of two cold desert shrubs. American Journal of Botany. 1999; 86:11461153.

14. Dhanda SS, Sethi GS, Behl RK. Indices of drought tolerance in wheat genotypes at early stages of plant growth. Journal of Agronomy Crop Science. 2004; 190:612.

15. El-Mohsen AA, El-Shafi MA, Gheith E, Suleiman H. Using different statistical procedures for evaluating drought tolerance indices of bread wheat genotypes. Advance in Agriculture and Biology. 2015; 4(1):19-30.

16. Fraser T, Silk W, Rosr T. Effect of low water potential on cortical cell length in growing region on maize roots. Plant Physiology. 1990; 93:648-651.

17. Guoth A, Tari I, Galle A, Csiszar J, Pecsvaradi A, Cseuz L, Erdei L. Comparison of the drought stress responses of tolerant and sensitive wheat cultivars during grain filling: changes in flag leaf photosynthetic activity, ABA levels, and grain yield. Journal of Plant Growth Regulator. 2009; 28:167-176.

18. Hunter JR, Erickson AE. Relation of seed germination to soil moisture tension. Agronomy Journal. 1952; 44:107109.

19. Heikal MM, Shaddad MA, Ahmed AM. Effect of water stress and gibberellic acid on germination of flax, sesame and onion seed. Biological Plantarum. 1981; 24(2):124129.

20. Huang B, Gao H. Physiological responses of diverse tall fescue cultivars to drought stress. Horticulture Science. 1999; 34:897-901.

21. Hsiao TC, Xu LK. Sensitivity of growth of roots versus leaves to water stress: biophysical analysis and relation to water transport. Journal of Experimental Botany. 2000; 51:1595-1616.

22. Huang $\mathrm{B}, \mathrm{Fu}$ J. Photosynthesis respiration and carbon allocation in two cool season perennial grasses in response to surface soil drying. Plant Soil. 2000; 227:1726.

23. Homayoun H, Sam DM, Mehrabi P. Study of PEG stress effect on wheat cultivar at germination stage. MiddleEast Journal Science Research. 2011; 9(1):71-74.

24. Hamza JH. Seed Priming of Bread Wheat to Improve Germination Under Drought Stress. Iraqi Journal of Agricultural Sciences. 2012; 43(2):100-107.

25. Harshvardhan NZ, Tejas CB, Kalyani SK, Yogesh MS. Physiological and biochemical characterization for drought stress at seedling stage in wheat genotypes International. Journal of Bio-resource and Stress Management. 2014; 5(3):386-394.

26. Hassan MI, Mohamed EA, El-Rawy MA, Amein KA. Evaluating interspecific wheat hybrids based on heat and drought stress tolerance. Journal of Crop Science and Biotechnology. 2016; 19(1):85-98.

27. Iqbal M, Ashraf M. Seed treatment with auxins modulates growth and ion partitioning in salt-stressed wheat plants. Journal Integrated Plant Biology. 2007; 49:1003-1015.

28. Kramer PJ. Water Relations of Plants. Academic Press, Inc. California. 1983, 16. 
29. Kim YJ, Yun SJ, Park HK, Park MS. A Simple method of seedling screening for drough tolerance in soybean. Korean Journal of Crop Science. 2014; 6(4):284-288.

30. Khan MQ, Anwar S, Khan MI. Genetic variability for seedling traits in wheat (Triticum aestivum L.) under moisture stress conditions. Asian Journal of Plant Science. 2002; 1:588-590.

31. Kaya MD, Okcu G, Atak M, Cikili Y, Kolsarici O. Seed treatments to overcome salt and drought stress during germination in sunflower (Helianthus annus L.). Europian Journal of Agronomy. 2006; 24:291-295.

32. Kulkarni M, Deshpande U. In-vitro screnning of tomato genotypes for drought resistance using polyethylene glycol. African Journal of Biotechnology. 2005; 6:691696.

33. Kaydan D, Yagmur M. Germination, seedling growth and relative water content of shoot in different seed sizes of triticale under osmotic stress of water and $\mathrm{NaCl}$. African Journal of Biotechnology. 2008; 7(16):2862-2868.

34. Kamran M, Shahbaz M, Ashraf M, Akram NA. Alleviation of drought induced adverse effects in spring wheat (Triticum aestivum L.) using proline as a presowing seed treatment. Pakistan Journal of Botany. 2009; 41(2):621-632.

35. Khan AS, Allah SU, Sadique S. Genetic variability and correlation among seedling traits of Wheat (Triticum aestivum) under water stress. International Journal of Agriculture Biology. 2010; 12(2):247-250.

36. Khakwani AA, Dennett MD, Munir M. Drought tolerance screening of wheat varieties by inducing water stress conditions. Songklanakarin Journal of Science and Technology. 2011; 33(2):135-142.

37. Khan MI, Shabbir G, Akram Z, Shah MKN, Ansar M, Cheema MN et al. Character association studies of seedling traits in different Wheat genotypes under moisture stress conditions. Journal of Breeding and Genetics. 2013; 45(3):458-467.

38. Lagerwerff JV, Ogata G, Eagle HE. Control of osmotic pressure of culture solutions with polyethylene glycol. Science. 1961; 133:1486-1487.

39. Lu Z, Neumann PM. Water-stressed maize, barley and rice seedlings show species diversity in mechanisms of leaf growth inhibition. Journal of Experimental Botany. 1998; 49:1945-1952.

40. Liu X, Huang B. Heat stress injury in relation to membrane lipid membrane maintenance in tall fescue. Crop Science. 2000; 32:251-256.

41. Morgan JM. Osmoregulation and water stress in higher plants. Annual. Review of Plant Physiology. 1984; 35:299-319.

42. Munns R, Sharp RE. Involvement of abscisic acid in controlling plant growth in soil of low water potential. Australian Journal of Plant Physiology. 1993; 20:425437.

43. Money NP. Osmotic pressure of aqueous polyethylene glycols. Relation between molecular weight and vapor pressure deficit. Plant Physiology. 1989; 91:497-500.

44. Manoj K, Uday D. In vitro screening of tomato genotypes for drought resistance using polyethylene glycol. African Journal of Biotechnology. 2007; 6(6):691-696.

45. Murillo-Amador BR, Lopez-Aguilar RC, Kaya J, Larrinaga-Mayoral, Flores-Hernandez A. Comparative effects of $\mathrm{NaCl}$ and polyethylene glycol on germination, emergence and seedling growth of Cowpea. Journal of Agronomy Crop Science. 2002; 188:235-247.
46. Moucheshi A, Heidari B, Assad MT. Alleviation of drought stress effects on wheat using arbuscular mycorrhizal symbiosis. International Journal of Agricultural science. 2012; 291:35-47.

47. Mujtaba SM, Summiya F, Khan MA, Saba M, Barkat K. Physiological studies on six wheat (Triticum aestivum L.) genotypes for drought stress tolerance at seedling stage. Agriculture Research and Technology. 2016; 1(2):1-6

48. Noorka IR, Khaliq I. An efficient technique for screening wheat (Triticum aestivum L.) germplasm for drought tolerance. Pakisthan Journal of Botany. 2007; 39(5):1539-1546.

49. Okcu G, Kaya MD, Atak M. Effect of sat and drought stresses on germination and seedling growth of pea (Pisum sativum L.). Turkish Journal of Agriculture. 2005; 29:237-242.

50. Othmani A, Sourour A, Slama-Ayed O, Slim-Amara H, Mongi BY. Durum wheat response (Triticum durum Desf.) to drought stress under laboratory conditions. IOSR Journal of Agriculture and Vegetable Science. 2019; 12(2):1-4

51. Perez JER, Juan MS, Gabriela ML, Rafael MA, Jaime SC. Wheat (Triticum aestivum L.) and triticale ( $X$ Triticosecale Witt.) germination under moisture stress induced by polyethylene glycol. African Crop Science Conference Proceedings. 2007; 8:27-32.

52. Rakesh V, Sethi SS, Vashnavi R. Relative drought tolerance of rye-introgressed bread wheat (Triticum aestivum L.) genotypes in osmoticum. Annals Biols. Ludhiana. 1998; 14(2):169-173.

53. Rauf M, Munir M, Hassan M, Ahmad M, Afzal M. Performance of wheat genotypes under osmotic stress at germination and early seedling growth stage. African Journal of Biotechnology. 2006; 6:971-975.

54. Soni P, Sharma R, Rizwan M, Singh G. Optimization of screening protocol for evaluation of drought tolerance in Vignaconitifolia using hydroponic system. Indian Research Journal of Genetics Biotechnology. 2014; 6(4):617-28.

55. Sayar R, Bchini H, Mosbahi M, Khemira H. Response of durum wheat (Triticum durum Desf.) growth to salt and drought stresses. Czech Journal of Genetic Plant Breeding. 2010; 46(2):56-63.

56. Verslues PE, Bray EA. LWR 1 and LWR 2 are required for osmoregulation and osmotic adjustment in Arabidopsis. Plant Physiological Preview. 2004; 1:28312842.

57. Verslues PE, Bray EA. Role of abscisic acid (ABA) and Arabidopsis thaliana ABA- insensitive loci in low water potential induced ABA and proline accumulation. Journal of Experimental Botany. 2006; 1:201-212.

58. Van den Berg L, Zeng Y. Response of South African indigenous grass species to drought stress induced by polyethylene glycol (PEG) 6000. South African Journal of Botany. 2006; 72(2):284-286.

59. Zhu JK, Hasegawa PM, Bressan RA. Molecular aspect of osmotic stress in plants. Critical Rev. In Plant Science. 1997; 16:253-277.

60. Zhu J. Effects of drought stresses induced by polyethylene glycol on germination of Pinus sylvestris var. mongolica seeds from pollination forests on sandy land. Natural and Polination Forests on sandy Land Journal of Forest Research. 2006; 11(5):319-328. 